\title{
Use of Virtual Reality for the Therapy of Children with Attention Deficit Hyperactivity Disorder
}

\author{
Miroslav Musalek ${ }^{1 *}$, Ivan Kovar ${ }^{1}$ and Tomas Sysala ${ }^{1}$ \\ ${ }^{1}$ Tomas Bata University - Faculty of Applied Informatics, Nad Stranemi 4511, Zlin, 760 05, Czech Republic
}

\begin{abstract}
The subject of this article is to find out if there is any possibility that virtual reality (VR) can help to heal the people with attention deficit hyperactivity disorder (ADHD). The aim of the suggested and realized pre-research was to find out if it is possible to help children to deal with ADHD. We organized a pre-research with the use of Samsung Gear VR device on a small sample of examined respondents with ADHD. Initial results are obtained from questionnaire method of a specialized test SNAP-IV. Table shows improvement of mental state of respondents in case of use new modern VR methods. Treatment of ADHD is often difficult, take a lot of time and it is performed mostly with pharmaceuticals or hypnotic sleep medications. This pre-research presents a method that could speed up therapy and also reduce the use of pills which is very important. Discussion and evaluation of the pre-research are included.
\end{abstract}

\section{Introduction}

This article focuses on the use of VR in treating people, especially children with ADHD. In today's modern society, there are stimuli that can cause many diseases. ADHD is one of the most observed psychiatric diseases of children.

In articles $[1,2]$ can be seen an increase of ADHD in children, it is almost 25 percent of the past decade.

The aim of this pre-research was to test the possibilities of VR to reduce ADHD. A virtual environment is a safe and painless form of therapy. The user is under control during the therapy. Another advantage is easy handling, control of the environment and the ability to react promptly to unexpected events.

The article [3] examined 20 relevant studies that had used VR technologies in the diagnosis, treatment, assessment, and training of children with ADHD. In the article, it has been shown that VR, through user interaction with the created virtual environment, is able to increase users' concentration. The studies investigated show positively that the VR environment affects a wide range of human emotions. Last but not least, it has been shown that this virtual environment is suitable for a combination of using the medicament.

According to the research described in [4] allows a controlled VR environment to monitor the patient's condition. This method starts to be useful for neuroscience application. VR can be easily calibrated to the rehabilitation requirements of ADHD.
In the article [5] there are more factors that influence the successful rehabilitation of ADHD. This research has shown the positive impact of the virtual environment that allowed children to start interactive things that they would not experience in the real world.

The upshot from such studies is that although VR holds a lot of promise, we still have to keep in mind that this approach is still new and still evolving.

\subsection{Attention deficit hyperactivity disorder}

This disorder has many definitions, such as:

"Abbreviation of ADHD: from the terminology of the American Psychiatric Association - it is on the label for attention deficit syndrome associated with hyperactivity syndrome attention deficit without the presence of hyperactivity (ADD). " [6]

"Children with ADHD chronically suffer from inattention, overactivity and impulsivity. These characteristics manifest themselves significantly in the early stages of development, more clearly than their mental age. " [7]

It can be said that an individual suffering from ADHD is struggling with impulsiveness, lack of attention and possibly hyperactivity.

Basic symptoms of ADHD:

- attention failure

- hyperactivity

- impulse

* Corresponding author: musalek@utb.cz 
Associated failures:

- Perception of motor disorders

- memory disorders

- speech disorders

- emotional disorder

- behavioral disorders

- learning disabilities [7]

Individual developmental stages of the disorder:

- children from birth to 3 years old

- preschool children

- younger school age

- adolescence and early adulthood

The treatment of ADHD is essential to effectively reduce the symptomatology that affects the patient's life. As well as the treatment of all mental disorders, the treatment of ADHD always involves the cooperation of both the physician - especially the psychiatrist and the psychologist - in children in cooperation with parents and teachers. According to [8] may be involved in therapy for a child:

- examining doctor

- family practitioner

- class teacher

- school or counseling psychologist

- special-pedagogical care

- school nurse and doctor

- social services

- family therapists

- wider family and interest groups

- parental support organizations for children with ADHD

\subsubsection{Educational therapy}

In children with ADHD, the behavior is problematic. Therefore, we need to focus on adopting the right behaviour patterns. Here it is important that your child is aware of the consequences of your behavior. According to a recommendation from [9], [10], [11] it is good to implement the rules that children will follow. Their follow-up will be rewarded.

\subsubsection{School influence}

The teacher must understand the child's diversity. Differences can consist of intelligence, coordination, and temperament. Author [12] points to the use of teaching aids and teachers' collaboration with the professionals.

\subsubsection{Movement therapy}

Pursuant to [13], it is good to use coordination games that allow children to better orient themselves in space and to realize their body.

\subsubsection{Pharmacotherapy}

Correct medication can help a person with moderate or severe ADHD impairing their symptoms. However, pharmacotherapy cannot cure the disorder in general. Currently, only three preparations are registered in the Czech Republic. Stimulants are methylphenidate in two dosage forms, and there is non-stimulant drug atomoxetine.

According to [14] is necessary cardiologist examination, consent to initiation of treatment and follow-up in cardiology clinic for the duration of pharmacological therapy. Especially for people with a family history with heart problems.

In the article [15] is proven that behavioral oriented psychosocial treatment, along with pharmacotherapy, is a fundamental therapeutic approach to ADHD.

This pre-research dealt with a group of children. In children of this age range, approximately from six to twelve years old, ADHD symptoms are often fully developed. Their disorders are associated with hyperactivity, impulsivity and attention deficit disorder. Postponement of school attendance is no exception here. An important factor here is the school and family environment. In addition to educators in the school environment, rehabilitation can address these problems.

\subsection{Virtual reality}

VR is a computer-generated simulated environment. Compared to previous approaches, the VR user can completely absorb the situation in the created environment. Thus, the user does not track the scenes but is part of them. The virtual 3D environment created can act on the user's senses such as vision, hearing or touch. These senses are most often stimulated by conventional headsets. This pre-research used a virtual system from Samsung Gear VR with Controller.

\subsubsection{Samsung Gear VR}

Samsung Gear VR headset uses a mobile phone to calculate the virtual environment. This device can be seen in Fig. 1.

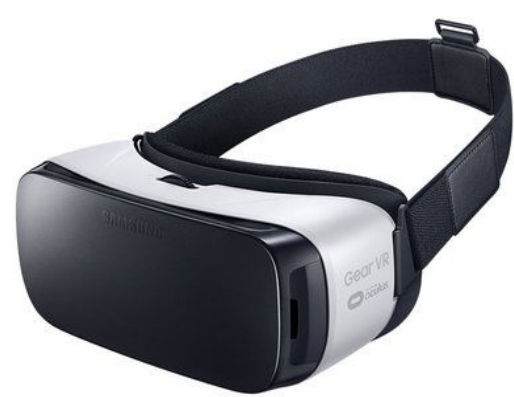

Fig. 1. Samsung Gear VR. 
This device provides an affordable solution for creating a virtual environment. This VR HMD technology transfers users to a virtual environment through the powerful computing capacity of a smartphone with an android. In addition, this technology is combined with Oculus head-tracking. Compared to other VR environments, there is no special display. To the user in the VR situation, the phone screen is used as the stereoscopic display. Controllers can be used for more interactive options. [16]

The disadvantage of this device is especially the whole dependence on the mobile phone. Accordingly, the quality of the VR environment or usage time is different. A system of double lenses standard for VR is installed in the glasses. The viewing angle in the used model is 101 degrees. Negative observational phenomena include, for example - blur, pixels, a decrease in quality at the edges, a feeling of cartoon graphics where you do not need it. The quality of the perceived virtual environment will be based on the resolution of the mobile phone display. Using virtual reality can cause feelings of nausea or dizziness. Samsung Gear VR does not allow you to adjust the distance between lenses, which causes eye fatigue and distorts and reduces image quality. Therefore, from these limiting factors, testing and measurement were done with for two hours for each person. [16]

\section{Results and discussion}

We have questioned whether VR can be useful in the ADHD healing process of people, especially young children.

\subsection{Presentation of pre-research}

At the beginning of the pre-research, we met individually with all the respondents and their parents in order to have a more detailed interview for understanding and detailed knowledge of their personal situation. The pre-research worked with two children (11 and 12 years old) suffering from ADHD. This preresearch was conducted from February to the end of April 2019 (3 months) in Zlin, Czech Republic. Basic information about the children involved in the preresearch can be seen in Table 1 .

In Fig. 2 and Fig. 3 can be seen by respondent 2 during his therapy.

Table 1. Personal data of respondents.

\begin{tabular}{|c|c|c|}
\hline & $\begin{array}{c}\text { Responden } \\
\mathrm{t} 1\end{array}$ & $\begin{array}{c}\text { Responden } \\
\mathrm{t} 2\end{array}$ \\
\hline Gender & Male & Male \\
\hline
\end{tabular}

\begin{tabular}{|c|c|c|}
\hline Age & 11 & 12 \\
\hline Medication & No & No \\
\hline Attacks & Yes, often & Yes, \\
\hline $\begin{array}{c}\text { Approgularly } \\
\text { year in } \\
\text { which they } \\
\text { first } \\
\text { experienced } \\
\text { ADHD }\end{array}$ & 2015 & 2014 \\
\hline
\end{tabular}

There were 30 sessions in total with each respondent and everyone was exposed to VR effect for two hours on every session. There were the sessions regularly every week. At the sessions 1, 10, 15, 20, 25 and 30 during this pre-research, parents of the participants underwent the same process in which they completed various ADHD tests about their children and how they experienced their behavior from the last time.

Each session consists of 90 minutes of VR therapy with the addition of 30 minutes of relaxation phase.

Based on the individual interviews, unique $360^{\circ}$ video material for VR was prepared individually for each respondent. These materials were designed to help to calm down, slow down breathing, focus and relax. As a reward, there was a relaxation phase always at the end of each session. This phase was designed to help children with relaxation and easing their stress and nerves. The respondents had the choice to choose some entertainment applications, for example, adventure games, simulation games or any VR cartoon fairy tale.

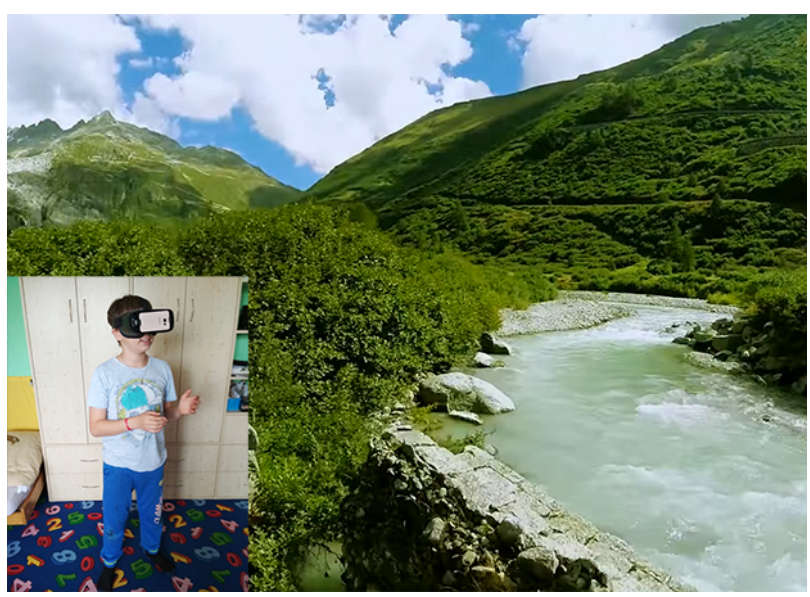

Fig. 2. Respondent 2 during his VR relaxation therapy. 


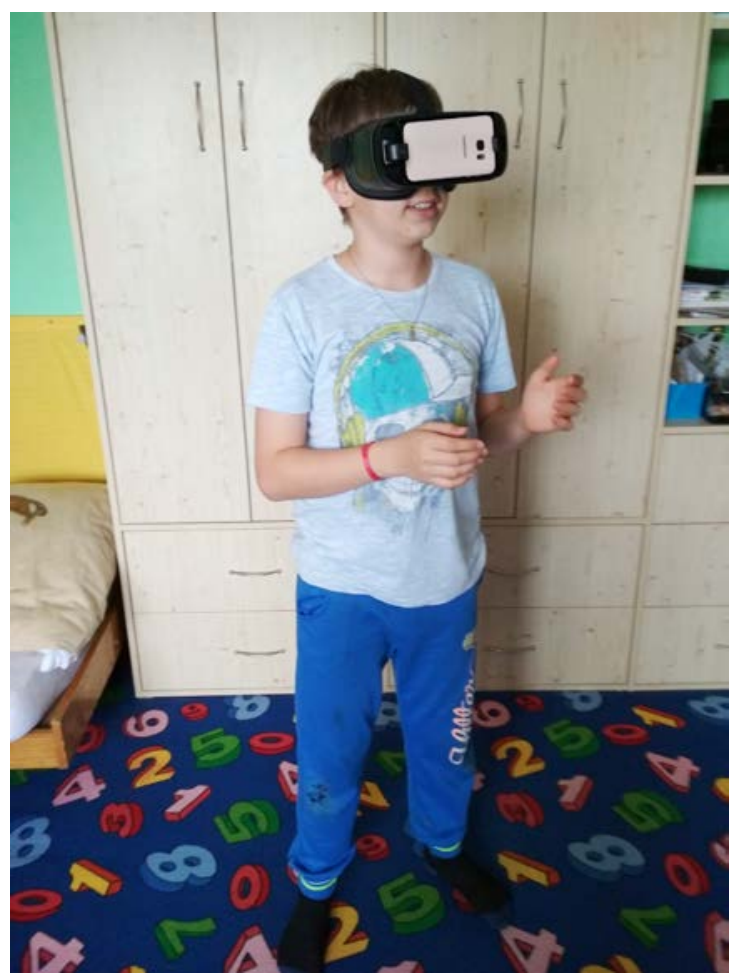

Fig. 3. Respondent 2 during his VR therapy.

\subsection{ADHD measurement}

The psychological status of respondents was investigated with the use of ADHD 26-item test SNAP-IV.

\subsubsection{SNAP-IV}

The SNAP-IV test is psychometrically easily accessible and simple to interpret comprehensive ADHD rating test. This tool effectively recognizes a distinction if a child has or does not have ADHD and accurately predicts presentation specifiers. [17]

Three different subsets are evaluated in this 26-item test. Questions from 1 to 9 are focused on inattention subset, questions from 10 to 18 are about the hyperactivity/impulsivity subset and questions from 19 to 26 are focused on the area of opposition/defiance subset. [18]

This test is based on 0 to 3 question rating scale: Not at all $=0$, Just a little $=1$, Often $=2$, and Very often $=3$. The scores in each of the three subsets (inattention, hyperactivity/impulsivity, and opposition/defiance) are totalized. For the inattention and hyperactivity/impulsivity subsets, the maximum total score is 27 points. If the gained score is lower than 13 points, it is possible to talk about not clinically significant symptoms of a disorder. If the gained score is between 13 and 17 points, it is considered as mild symptoms of a disorder. If the score is between 18 and 22 points, it is already diagnosed as moderate symptoms of a disorder. Score with 23 and more points is classified as severe symptoms of a disorder. [18]

For the opposition/defiance subset, the maximum total score is 24 points. If the gained score is lower than 8 points, it is possible to talk about not clinically significant symptoms of a disorder. If the gained score is between 8 and 13 points, it is considered as mild symptoms of a disorder. If the score is between 14 and 18 points, it is already diagnosed as moderate symptoms of a disorder. Score with 19 and more points is classified as severe symptoms of a disorder. [18]

The gained results of SNAP-IV test from the individual measurements can be seen in Table 2 .

\section{Discussion}

Certainly, the impact and effect of ADHD VR therapy of children can be boosted. For example, with using a more sophisticated type of VR device, the overall VR experience could be better, richer and deeper. VR device Samsung Gear VR, which was used in the presented preresearch allow only static VR experience. It means, there is no real movement like in a real life and there is no touch response.

Table 2. Results of SNAP-IV measurement.

\begin{tabular}{|c|c|c|c|c|c|c|c|c|}
\hline & & $\begin{array}{c}\text { Sessio } \\
\text { n 1 }\end{array}$ & $\begin{array}{c}\text { Sessio } \\
\text { n 10 }\end{array}$ & $\begin{array}{c}\text { Sessio } \\
\text { n 15 }\end{array}$ & $\begin{array}{c}\text { Sessio } \\
\text { n 20 }\end{array}$ & $\begin{array}{c}\text { Sessio } \\
\text { n 25 }\end{array}$ & $\begin{array}{c}\text { Sessio } \\
\text { n 30 }\end{array}$ & $\begin{array}{c}\Delta \text { ma } \\
\text { x }\end{array}$ \\
\hline \multirow{3}{*}{ in attention subset } & $\begin{array}{c}\text { Resp. } \\
1\end{array}$ & 22 & 22 & 21 & 20 & 20 & 18 & 4 \\
\cline { 2 - 9 } & Resp. & 20 & 19 & 17 & 18 & 17 & 17 & 3 \\
\hline
\end{tabular}




\begin{tabular}{|c|c|c|c|c|c|c|c|c|}
\hline & 2 & & & & & & & \\
\hline \multirow{2}{*}{$\begin{array}{c}\text { hyper activity/impul } \\
\text { sivity subset }\end{array}$} & \begin{tabular}{c} 
Resp. \\
\cline { 2 - 9 }
\end{tabular} & 24 & 24 & 22 & 20 & 20 & 18 & 6 \\
\hline $\begin{array}{c}\text { Resp. } \\
\text { opposition/d efiance } \\
\text { subset }\end{array}$ & $\begin{array}{c}\text { Resp. } \\
1\end{array}$ & 19 & 19 & 17 & 16 & 15 & 15 & 4 \\
\cline { 2 - 10 } & $\begin{array}{c}\text { Resp. } \\
2\end{array}$ & 20 & 20 & 19 & 17 & 17 & 15 & 5 \\
\hline
\end{tabular}

For example, with HTC Vive VR device, there would be a more authentic simulation of walking in 3D virtual surrounding or holding of something. According to our experience, these functions could be more interesting and intensive for these young children to play and interact more in the VR environment.

\section{Conclusion}

The most important question of this paper was to find out if VR can be used as a tool to help and heal children suffering from ADHD. ADHD disrupts their whole life their relationships, their well-being and their happiness from everyday activities.

The results of our SNAP-IV test after the application of 3-month long intensive pre-research intervention at the time intervals are promising because there are provable decreases in ADHD level. These results are expressed in quantity $\Delta$ where the biggest value $\Delta \max$ was measured for the respondent 1 with $\Delta \max =6$ in the SNAP-IV hyperactivity/impulsivity subset. In SNAP-IV inattention subset, the biggest value $\Delta \max$ was measured for the respondent 1 with $\Delta \max =$ 4. The situation in SNAP-IV opposition/defiance subset was following, the biggest value $\Delta \max =5$ in this test was measured for the respondent 2 .

Although this pre-research was done only with a small group of children who are affected by ADHD, it appears that VR can be useful in medical areas. To be sure with the argument that VR has a markedly important role in dealing with ADHD, it is relevant to make bigger research in which a larger sample of respondents and more ADHD tests will be investigated. This kind of extended research is further prepared.

There was a help for this research by grant no. IGA/CebiaTech/2019/003 from Tomas Bata University in Zlin.

\section{References}

[1] Xu G, Strathearn L, Liu B, Yang B, Bao W. Twenty-Year Trends in Diagnosed AttentionDeficit/Hyperactivity Disorder Among US Children and Adolescents, 1997-2016. JAMA Netw Open. (2018);1(4):e181471.

doi:10.1001/jamanetworkopen.2018.1471

[2] Getahun D, Jacobsen SJ, Fassett MJ, Chen W, Demissie K, Rhoads GG. Recent Trends in Childhood Attention-Deficit/Hyperactivity Disorder. JAMA Pediatr. (2013);167(3):282-288. doi:10.1001/2013.jamapediatrics.401

[3] Bashiri A, Ghazisaeedi M, Shahmoradi L. The opportunities of virtual reality in the rehabilitation of children with attention deficit hyperactivity disorder: a literature review. Korean $\mathrm{J}$ Pediatr. (2017);60(11):337-343.

doi:10.3345/kjp.2017.60.11.337

[4] Diaz-Orueta, Unai et al. 'Virtual Reality for Neuropsychological Assessment'. Virtual, Augmented Reality and Serious Games for Healthcare edited by Minhua Ma, Lakhmi C. Jain, Paul Anderson. Springer Science \& Business, (2014).

[5] Gongsook, Pongpanote. Time Simulator in Virtual Reality for Children with Attention Deficit Hyperactivity Disorder. (2012), 7522. 490-493. 10.1007/978-3-642-33542-6_61.

[6] D. Jucovičová, H. Žáčková. Uneasy and restless child in school and family, Prague: Grada. [7] PACLT, Ivo et al. Hyperkinetic disorder and behavioral disorders. Prague: Grada.

[8] A. Munden and J. Arcelus. Attention and Hyperactivity Disorders: Overview current knowledge and approaches for parents and professionals. Ed. 2. Prague: Portal. Special Pedagogy (Portal).

[9] G. Serfontein. Problems of children with learning and behavior. Prague: Portal. Counselors for parents and educators.

[10] CARTER, Cheryl R.. Child with ADHD and $A D D$ at home and school: a practical guide for parents and teachers. Prague: Portal.

[11] Laver-Bradbury, C. (2010). A self-help manual for parents. London: Jessica Kingsley Publishers.

[12] A. Train. ADHD : how to deal with very difficult children. London: Souvenir Press, (1996). Print.

[13] M. Blahutková, J. Klenková and D. Zichová. Psychomotor games for children with attention 
deficit disorders and for hyperactive children. Brno (2005): Masaryk University.

[14] Wilens TE, Prince JB, Spencer TJ, et al. Stimulants and sudden death: what is a physician to do? Pediatrics (2006); 118: 1215-1219.

[15] Pelham WE Jr, Fabiano GA. Evidence-based psychosocial treatments for attentiondeficit/hyperactivity disorder. J Clin Child Adolesc Psychol (2008); 37: 184-214.

[16] Specifications Samsung Gear VR. Available: https://www.samsung.com/global/galaxy/gear$\mathrm{vr} / \mathrm{specs} /$

[17] Swanson JM, Kraemer HC, Hinshaw SP, Arnold LE, Conners CK, Abikoff HB, Clevenger W, Davies M, Elliott GR, Greenhill LL, Hechtman L, Hoza B, Jensen PS, March JS, Newcorn JH, Owens EB, Pelham WE, Schiller E, Severe JB, Simpson S, Vitiello B, Wells K, Wigal T, Wu M. Clinical relevance of the primary findings of the MTA: success rates based on severity of $A D H D$ and $O D D$ symptoms at the end of treatment. J Am Acad Child Adolesc Psychiatry. (2001) Feb;40(2):168-79.

[18] R. Bussing, M. Fernandez, M. Harwood, W. Hou, C. W. Garvan, S. M. Eyberg and J. M. Swanson. Parent and Teacher SNAP-IV Ratings of Attention Deficit Hyperactivity Disorder Symptoms. Assessment. (2008), 15(3), 317-328. DOI: $10.1177 / 1073191107313888$ 